\title{
Prospective randomised trial of laser therapy only and laser therapy followed by endoscopic intubation for the palliation of malignant dysphagia
}

\author{
H Barr, N Krasner, A Raouf, R J Walker
}

\begin{abstract}
Forty six consecutive patients admitted for the relief of malignant dysphagia were prospectively randomised to receive laser therapy only or initial laser therapy followed by endoscopic intubation. Twenty patients were treated in each group with six exclusions. The patients' swallowing ability was assessed before and during the remainder of their life on a $0-4$ scale with 0 being normal swallowing and 4 total dysphagia. The patient's quality of life was measured at the same times, using a physician's assessment ( $Q L$ index) and the patient's own assessment using a linear analogue self assessment (LASA). There was a significant correlation between all the $Q \mathbf{L}$ index and the LASA scores collected $\left(n=126 ; r_{s}=0.594\right.$, $\mathrm{p}<0.001$ ). The mean monthly dysphagia grade correlated with the $Q L$ index $\left(r_{s}=0.433\right.$, $\mathbf{p}<0.001)$ and the LASA $\left(r_{s}=0.272, p<0.002\right)$. There was no significant difference in the dysphagia grade before or after treatment in either group. Dysphagia fluctuated more in those treated with the laser only, however, than in those with a tube inserted. There was also no significant difference in the quality of life measured between the two groups of patients. The complication rate (laser only $10 \%$, laser/intubation $40 \%, p<0.05$ ) was significantly higher in intubated patients. The recurrent dysphagia rate (laser only $25 \%$, laser/ intubation $45 \%$, NS) was higher in patients treated with intubation, but they required fewer endoscopic procedures. Overall both procedures were effective in relieving dysphagia and in maintaining quality of life. There was no procedure related mortality in either group.
\end{abstract}

The symptoms of advanced carcinoma of the oesophagus and gastric cardia require effective treatment, if the patient is not to experience distressing dysphagia, regurgitation, dehydration and malnutrition. Surgical resection and radiotherapy can be curative, but only $18 \%$ of patients treated are alive one year after treatment. ${ }^{12}$ Local tumour invasion, however, means that in up to $75 \%$ of patients resection is purely palliative ${ }^{3}$, and in a recent large series only $38 \%$ of patients were considered resectable for cure or palliation. ${ }^{4}$ Radiotherapy is inappropriate for adenocarcinoma arising from the gastric cardia and may not provide adequate palliation. ${ }^{56}$ The main aim of treatment in most patients is therefore to provide palliation with a minimum morbidity from the treatment itself.

Intubation of the malignant stricture has proved to be a very useful technique and is becoming more widely used by gastroenterologists. ${ }^{7}$ Endoscopic intubation is associated with a lower morbidity and mortality than surgical insertion of the tube ${ }^{8}$ and has arguably become the first line treatment for patients for the palliation of malignant dysphagia. The overall efficacy of this technique is still debated, as normal swallowing may not be achieved, and the patients are generally advised to eat a semisolid or liquid diet, ${ }^{5}$ in particular if the tube is long or kinked by tumour. ${ }^{9}$ Also further dysphagia and tube dysfunction may occur in up to $44 \%$ of patients. ${ }^{10}$ More recently endoscopic laser therapy has been shown to be safe and effective in coring out a new lumen in the oesophagus and relieving dysphagia. ${ }^{112}$ These studies have shown that laser therapy must be repeated at monthly intervals if the improvement in dysphagia is to be maintained for the remainder of the patient's life. Even then some patients initially treated with the laser required endoscopic intubation because of extrinsic tumour compression or rapid tumour growth. Therefore, the ideal method for the endoscopic palliation of malignant dysphagia remains controversial, with some advocates for endoscopic intubation and some for endoscopic laser therapy. The aim of this investigation was to compare the efficacy of palliation using laser therapy with endoscopic intubation for the management of malignant dysphagia.

It may be assumed that the effectiveness of palliation for malignant dysphagia should be measured by the improvement in the patient's degree of dysphagia. Although generally acceptable it has become clear to us that the amount of improvement in the degree of dysphagia may not necessarily equate with the effectiveness of palliation. For instance a patient with widespread metastatic or advanced local disease may not be too concerned about eating a full meal, and indeed may have no appetite for this. Thus a minimal improvement in swallowing to a liquid diet may improve quality of life as much as an improvement to a normal diet. Because our main
Correspondence to: $\mathrm{DrN}$ Krasner, The Gastrointestina Lane, Liverpool

Accepted for publication

6 June 1989
The Gastrointestinal Liverpool

N Krasner

A Raouf 
interest was to improve the dying process experienced by these patients, a prospective assessment of the quality of life was performed throughout the study.

\section{Methods}

\section{PATIENTS}

The gastrointestinal unit at Walton hospital acts as a secondary referral centre for patients suffering with malignant dysphagia who are considered unfit or unsuitable for other forms of therapy. Some patients are referred after initial attempts at endoscopic intubation, which had failed because of total oesophageal occlusion. In a six year period 190 patients have been treated using endoscopic laser therapy; $21 \%$ of these patients had total occlusion and it was not possible to pass a guide wire to dilate the malignant stricture so endoscopic intubation was not an immediate option. Thus many of our patients would have been unsuitable for inclusion in a prospective trial if randomisation was directly to laser therapy or endoscopic intubation. We considered it important to randomise an unselected consecutive group of patients referred for treatment. Patients were randomised on referral to receive laser therapy only or initial laser therapy followed by endoscopic intubation using sealed envelopes.

Forty six consecutive patients were treated, twenty patients received laser therapy alone and twenty had initial laser therapy followed by endoscopic intubation. Six patients had to be excluded from the trial. Four patients were unsuitable for endoscopic intubation because the tumour was less than $2 \mathrm{~cm}$ from the upper oesophageal sphincter (two patients), the tumour was too long to be bridged by the available prostheses (one patient) and one patient had a large pharyngeal pouch which made intubation difficult. One patient was excluded because she had a tracheo-oesophageal fistula evident at the first endoscopic examination making intubation mandatory. One patient was initially entered in the trial but removed because of early tube slippage, the reason for which is explained below.

The patient details of the two groups are included in Table I. Nine patients had been initially considered by their gastroenterologist for endoscopic intubation but referred after this had failed generally because of difficulty with the passage of a guide wire. In these patients we were able to pass a guide wire in one and the laser fibre passed through the tumour in three patients after very minimal initial laser therapy. One patient was referred after the prosthetic tube had been dislodged into the stomach and the tumour would not dilate to allow the insertion of a second tube.

\section{METHODS OF TREATMENT}

\section{Laser only}

Patients were treated using a 100 watt neodymium yttrium aluminium garnet laser $(\mathrm{Nd}$ YAG); the first laser used was a Molectron 8000
TABLE I Details of the patients treated with laser therapy alone or laser therapy followed by endoscopic intubation

\begin{tabular}{|c|c|c|}
\hline & $\begin{array}{l}\text { Laser only } \\
(n=20)\end{array}$ & $\begin{array}{l}\text { Laser/intubation } \\
(n=20)\end{array}$ \\
\hline $\begin{array}{l}\text { Mean age (range) } \\
\text { M/F }\end{array}$ & $\begin{array}{l}73(36-94) \\
14 / 6\end{array}$ & $\begin{array}{l}71(53-87) \\
10 / 10\end{array}$ \\
\hline $\begin{array}{l}\text { Tumour } \\
\text { Squamous cell } \\
\text { Adenocarcinoma }\end{array}$ & $\begin{array}{r}8 \\
12\end{array}$ & $\begin{array}{r}6 \\
14\end{array}$ \\
\hline $\begin{array}{l}\text { Reason for palliation } \\
\text { Advanced local disease } \\
\text { Liver metastasis } \\
\text { Unfit for other therapy }\end{array}$ & $\begin{array}{l}9 \\
6 \\
5\end{array}$ & $\begin{array}{l}9 \\
4 \\
7\end{array}$ \\
\hline $\begin{array}{l}\text { Mean length of stricture } \\
(\text { range })(\mathrm{cm})\end{array}$ & $6 \cdot 2(2-12)$ & $6 \cdot 8(3-15)$ \\
\hline $\begin{array}{l}\text { Mean position of the upper } \\
\text { border of the tumour from } \\
\text { the incisor teeth (range) } \\
(\mathrm{cm})\end{array}$ & $35 \cdot 8(22-46)$ & $30 \cdot 2(23-38)$ \\
\hline $\begin{array}{l}\text { Patients with total luminal } \\
\text { occlusion (n) }\end{array}$ & 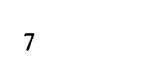 & 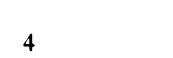 \\
\hline
\end{tabular}

laser (Molectron Medical, Cooper Lasersonics), which was subsequently replaced with a Fiberlase 100 (Living Technology, Glasgow). The laser emitted an invisible, infrared beam of $1064 \mathrm{~nm}$ transmitted down a $400 \mu$ flexible optical fibre. We have described our method of treatment in detail previously" and this is similar to that used by others. ${ }^{12}$ The patient was treated at endoscopy under sedation with intravenous midazolam (4-10 mg). If possible treatment was started at the distal end of the tumour, but in patients with total occlusion the laser was used to remove tumour from the upper surface working distally. Initially patients were treated at three to seven day intervals until a lumen equal to the size of the oesophagus was obtained. After these initial laser sessions, laser endoscopy was repeated at monthly intervals until death to prevent recurrent dysphagia. If the patient developed recurrent dysphagia early after laser therapy and required more frequent endoscopy, generally because of rapid tumour growth, laser therapy was considered to have failed and endoscopic intubation performed. In addition laser therapy was deemed to have failed and become inappropriate if the patient developed recurrent dysphagia because of extrinsic compression or fibrous stricture formation. In these circumstances endoscopic intubation was performed for immediate relief of dysphagia. For each laser session the patients were admitted overnight and discharged the following day. All laser therapy was performed by experienced operators (HB and NK). The patients were advised to eat what they liked and were not given any dietary restriction. All were advised to chew their food well and we ensured that they had adequate dentition to allow this.

\section{Laser therapy followed by endoscopic intubation}

Patients randomised to this form of treatment were initially treated by laser endoscopy. The laser was used to ensure that there was a lumen to allow passage of a guide wire, dilatation and placement of a prosthetic tube. No attempt was made to clear the oesophagus of all exophytic tumour, the major effort was to produce an even lumen, remove excessive angles and remove fleshy necrotic areas that would prevent proper anchoring of the tube, and so allow horizontal 
orientation. ${ }^{9}$ In 14 patients only one short laser session was performed before intubation and was not essential for adequate placement of the tube. Four patients required two laser sessions to ensure a good lumen. In two of these patients, it was not possible to pass through the tumour, and laser therapy was required to the upper end of the tumour before a guide wire could be passed and dilatation performed. The remaining two patients had several laser sessions (three and four sessions), starting at the upper end of the tumour before a lumen to allow dilatation was evident. Laser therapy was again performed by experienced operators (HB \& NK). Endoscopic intubation was performed 10-14 days after laser therapy to ensure that any necrotic tissue treated by the laser had separated and avoid the risk of early slippage of the prosthetic tube. Early slippage occurred in the two patients when the tube was inserted five days after laser therapy. We believe that slippage occurred when necrotic tumour separated and laser induced oedema resolved, loosening the anchorage of the tube. In one patient the tube could not be easily removed from the stomach. He was in the terminal stages of the disease and expressed reluctance at the prospect of repeat endoscopic intubation, so palliation was achieved using laser therapy only and the patient was excluded from the trial. In the other patient the tube was reinserted ( 10 days after laser therapy) without difficulty and did not subsequently move and is included in the trial. This problem was regarded as a complication of the combined procedure and is not included in subsequent analysis of complications. The method of insertion was that previously described using the Nottingham endoscopic devices and the largest possible Atkinson tube was inserted. ${ }^{1314}$ All endoscopic intubation was performed by those experienced in the technique (AR \& RJW) at least 10 days after laser therapy. It was this team's usual practice to perform a gastrograffin swallow after intubation to ensure that perforation had not occurred and that the tube was in a satisfactory position. No contrast radiology was performed after laser therapy unless specifically indicated. No specific dietary restriction was given to intubated patients and they were advised to eat what they liked provided that they chewed it well and took plenty of fluid. They were also advised to take carbonated drinks regularly.

\section{PATIENT ASSESSMENT}

\section{Dysphagia}

All patients had been referred for the relief of dysphagia. Swallowing difficulty was graded on a simple 0 to 4 scale: 0 able to swallow all solids without difficulty; 1 difficulty with swallowing some hard solids or particular food; 2 able to swallow a semisolid diet only; 3 able to swallow a liquid diet only; 4 unable to manage liquids and saliva. The scale was explained to each patient with examples of semisolid diet and liquid diet. Before treatment the patients were asked to grade the swallowing ability using this system. The patient was asked to keep a daily diary and grade his/her own swallowing ability at the end of every day. The mean dysphagia grade was calculated from this diary at the end of every month or whenever the patient brought their record to the hospital. In one blind patient, his family were asked to keep the record. One other patient had some difficulty keeping the record because of severe mental impairment and his diary was kept by his attendants. If the patient became incapacitated and was admitted to hospital or hospice and became disinclined or unable to keep the record, the attendants were asked to assess swallowing ability. Patients treated with intubation had their dysphagia grade assessed only after the prosthetic tube had been inserted and not during the period of laser therapy.

\section{QUALITY OF LIFE}

A prospective quality of life assessment was performed on all patients. Two methods were used, one involving the attending physician's assessment, and the other a patient's self assessment. The physician's quality of life measurement used the quality of life index (QLI). ${ }^{15}$ This index was devised to allow physicians to assess the benefits of palliative care. It consisted of a structured interview lasting approximately five minutes. It examined five specific items, activity, living, health, support, and outlook on life. Each was rated on a threepoint scale (0-2), with a minimum to maximum score from 0-10.

The second instrument used to measure quality of life used a linear analogue self assessment (LASA). ${ }^{16}$ This self assessment questionnaire was completed by the patient with a doctor or nurse in attendance to provide any explanation required. The sheet contained 25 visual analogue scales (VAS) consisting of lines, the length of which represented the continuum of some emotional, physical or social experience. All the lines were $10 \mathrm{~cm}$ long and the patient marked the line at the point felt to represent his or her present position. This position was measured with a ruler with 0 representing the worst of the symptom and $10 \mathrm{~cm}$ the best. All 25 measurements were added together to give a score from 0-250. Ten of the VAS examined the patient's physical condition, five examined the psychological effects of the disease, five the patient's social interactions and four the patient's personal relationships and one asked the patient to assess his/her own quality of life. One VAS examining the patients physical condition measured the patient's swallowing ability.

The patient's quality of life and dysphagia grade were measured immediately on admission before the first assessment endoscopy. The dysphagia diary was collected at every follow up visit and hospital admission (generally monthly intervals) and a new one issued. The quality of life was measured at the same times. It was necessary to assess the patient every time they attended the hospital to allow any deterioration or complication to be reflected in the quality of life assessment. If the patient was admitted to hospital a quality of life assessment was performed at weekly intervals. On three occasions this necessitated forms to be sent to the admitting hospital. 


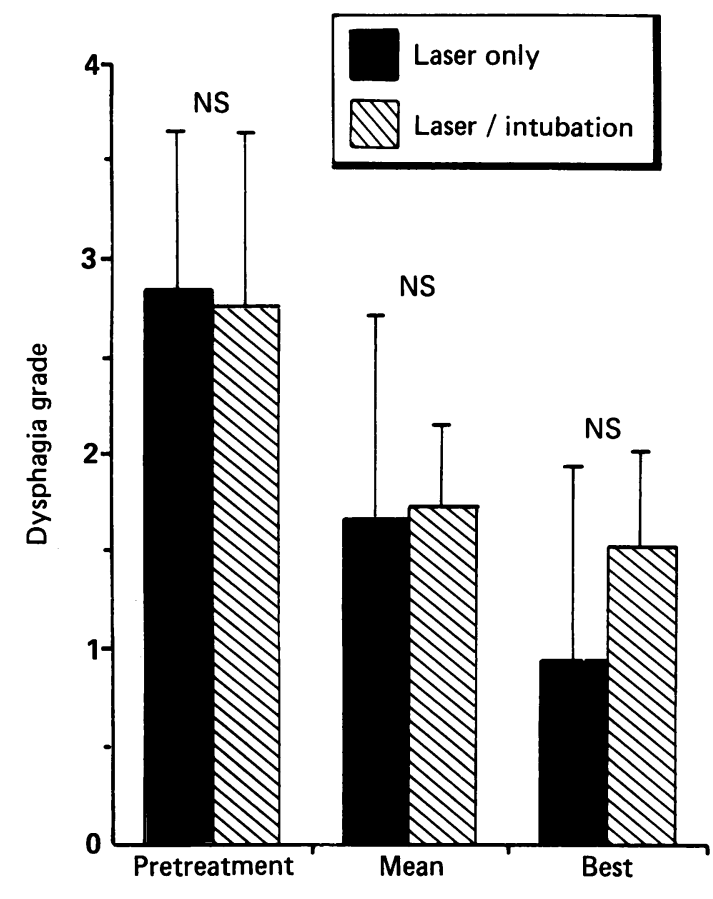

Assessment

Figure 1: Comparison of the dysphagia grade in patients treated with laser only or laser followed by endoscopic intubation. Pretreatment dysphagia assessment was for the week before the start of therapy. The mean is the mean of all the daily dysphagia grades recorded by the patient until death. The best assessment represents the mean of all the patients best recorded monthly dysphagia grade. The statistics are calculated using the Mann Whitney $U$ test.

\section{STATISTICAL ANALYSIS}

The significance of observed differences were assessed using the Mann-Whitney U test, Fisher's exact test, Wilcoxon's signed-rank test for paired observations and the correlation coefficient was calculated using Spearman's rank correlation.

\section{Results}

The results on the dysphagia of these patients are shown in Figure 1. The mean post treatment grade is the mean of all results recorded on the dysphagia diary after treatment. From each patient the month with the best mean dysphagia grade is presented as the mean best dysphagia grade. There was no significant difference in the pretreatment, the mean swallowing grade, and the best swallowing grade in either group. Eight patients treated with the laser only were eating a normal diet (grade 0 ) for at least three weeks at some time after the start of therapy. None of the patients with a prosthetic tube in place consistently recorded a normal diet at any time after intubation.

Table II shows the correlation coefficients

TABLE II Spearman correlation coefficients between dysphagia grade, QLI score and LASA score $(n=126)$.

\begin{tabular}{|c|c|c|}
\hline A & Dysphagia diary & \\
\hline $\begin{array}{l}\text { QLI } \\
\text { LASA }\end{array}$ & $\begin{array}{l}0.433 \\
0.272\end{array}$ & $\begin{array}{l}\text { Signincance } \\
\mathrm{p}<0.001 \\
\mathrm{p}<0.002\end{array}$ \\
\hline Q QLI & $\begin{array}{l}\text { LASA } \\
0 \cdot 594\end{array}$ & $\mathrm{p}<0.001$ \\
\hline $\begin{array}{l}\text { C } \\
\text { Dysphagia (mean for the } \\
\text { month before LASA) }\end{array}$ & $\begin{array}{l}\text { VAS dysphagia scale } \\
0.588\end{array}$ & $\mathrm{p}<0.001$ \\
\hline
\end{tabular}

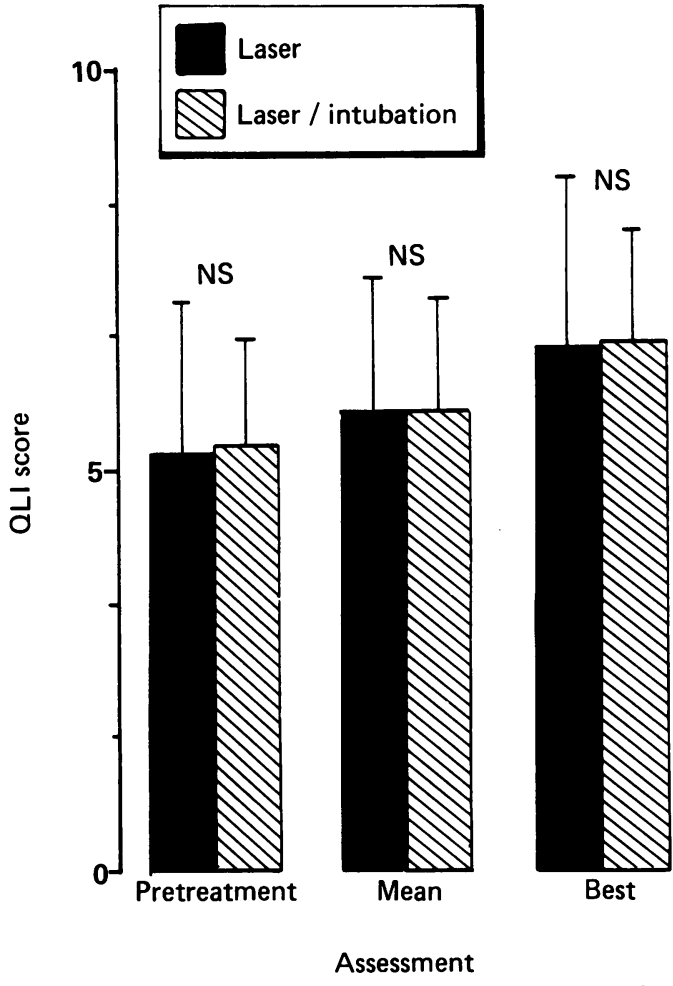

Figure 2: Comparison of the QLI score for patients treated with the laser only or the laser followed by endoscopic intubation. The assessments are the same as for Figure 1.

calculated for the dysphagia grade recorded from the diary cards, the VAS dysphagia scale taken from the LASA sheet, the QLI score, and the total LASA score.

\section{QUALITY OF LIFE}

Figures 2 and 3 show the QLI and LASA in both groups. There was no significant difference in the pretreatment, overall mean and mean best quality of life scores between the two groups.

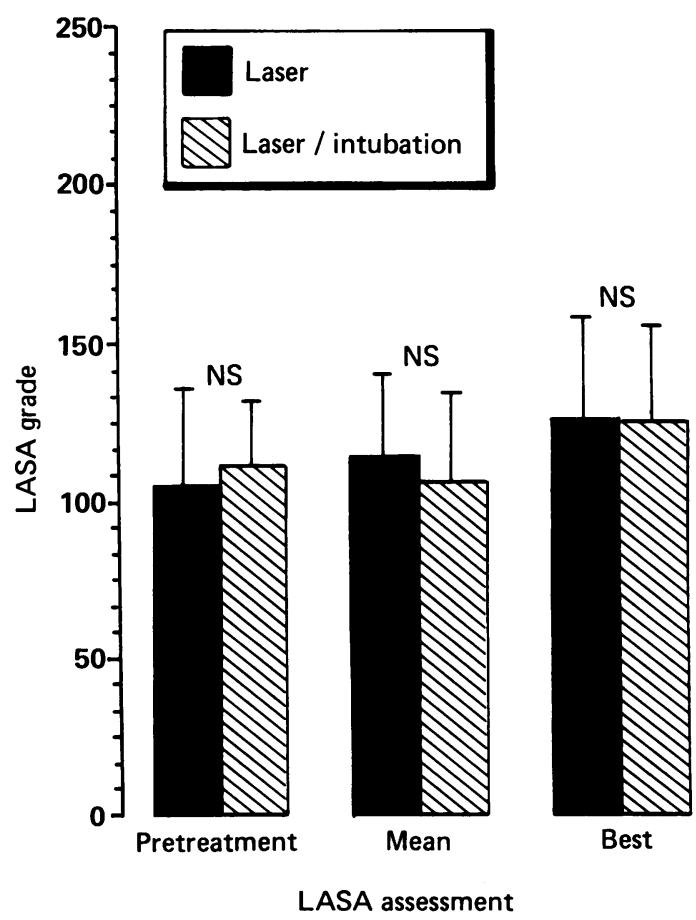

Figure 3: Comparison of the LASA scores for patients treated with the laser only or the laser followed by endoscopic intubation. The assessments are the same as for Figure 1. 
TABLE III Complications and survival data for the patients in both groups

\begin{tabular}{llll}
\hline & $\begin{array}{l}\text { Laser only } \\
(n=20)\end{array}$ & $\begin{array}{l}\text { Laser/intubation } \\
(n=20)\end{array}$ & NS \\
\hline $\begin{array}{l}\text { Mean survival (weeks) } \\
\text { Mean number of endoscopic } \\
\text { sessions }\end{array}$ & $18 \cdot 3$ & $16 \cdot 1$ & $\mathrm{~N}$ \\
$\begin{array}{c}\text { Mean number of nights in } \\
\text { hospital }\end{array}$ & $4 \cdot 6$ & $2 \cdot 9$ & $\mathrm{NS}$ \\
$\begin{array}{c}\text { Patients with complications } \\
(\%)(\mathrm{n})\end{array}$ & $13 \cdot 7$ & $11 \cdot 2$ & $\mathrm{NS}$ \\
$\begin{array}{c}\text { Patients with recurrent } \\
\text { dysphagia }(\%)(\mathrm{n})\end{array}$ & $2(10 \%)$ & $8(40 \%)$ & $\mathrm{p}<0.05$ \\
\hline
\end{tabular}

The mean best QLI in the laser group was 6.6 $(2 \cdot 13)$ and was significantly better than the mean pretreatment QLI of $5 \cdot 2(1.9)(\mathrm{p}<0.002$, Wilcoxon's signed-rank). The findings were similar in the patients treated by laser/intubation, the mean best QLI of 6.6 (1.4) was significantly better than the mean pretreatment QLI 5.3 (1.3) $(\mathrm{p}<0.002$, Wilcoxon's signed-rank $)$. In the laser only treated group the mean pretreatment LASA was 105 (31) with a mean best LASA of 125 (33) $(\mathrm{p}<0.02$, Wilcoxon's signed-rank); the mean pretreatment LASA in laser/intubation patients was $113(21)$ and reached a mean best LASA of 124 (32) $(\mathrm{p}<0.05$, Wilcoxon's signed-rank).

\section{RECURRENT DYSPHAGIA AND}

COMPLICATIONS

There was no procedure related mortality in either group of patients. The complication and recurrent dysphagia rate are summarised in Table III, with the survival data and mean number of endoscopic sessions required by patients in each group.

\section{Laser only (a) Recurrent dysphagia}

Five patients failed laser therapy because they developed recurrent dysphagia. Two developed severe dysphagia 14 and 20 days before the first and third repeat monthly laser endoscopy respectively. This was caused by rapid tumour growth and these were treated by endoscopic intubation. A further two patients developed extrinsic compression of the oesophagus as a result of extraluminal tumour. In one of these patients endoscopic intubation was performed 17 weeks after the initial laser endoscopy with relief of dysphagia. The other patient was able to manage a soft diet, although he had been eating a near normal diet previously, and intubation was not necessary and the patient's dysphagia grade did not deteriorate any further until death. One patient developed recurrent dysphagia caused by a large shelf of tumour distorting the stomach. The tumour was unsuitable for intubation and the patient was terminally ill, so no further treatment was offered.

\section{(b) Complications}

In the laser group two patients developed complications, both developed benign pneumatoperitoneum during a laser endoscopy session, ${ }^{17}$ with the coaxial gas escaping through the tumour during laser firing, but there was no evidence of perforation of the oesophagus on contrast radiology. Both patients were managed conservatively with intravenous fluids and antibiotics and they had their usual laser endoscopy session one month afterwards.

Laser/intubation (a) Recurrent dysphagia

Intubation was associated with more morbidity, nine patients had 10 episodes of recurrent dysphagia. Four patients developed food bolus obstruction, one patient had two episodes. In all instances the obstruction required repeat endoscopy to clear the tube. One patient had a complete tube displacement of the tube into the stomach six weeks after insertion. The oesophageal tumour was treated using the laser and the displaced tube caused intermittent epigastric discomfort. In four patients recurrent dysphagia was caused by tumour overgrowth of the tube causing upper end obstruction in three and lower end occlusion in one. All were successfully treated by laser vaporisation of the obstructing tumour. There was no significant difference between the recurrent dysphagia rate in either group.

\section{(b) Complications}

Excluding recurrent dysphagia eight patients developed complications. Two of these patients also had food bolus obstruction and one patient who had a pharyngeal perforation developed tumour overgrowth at a later date. Three patients were shown to have a small pharyngeal perforation on routine contast examination after intubation. Two patients were completely asymptomatic and one developed mild fever and pain. All were treated conservatively being placed on intravenous fluids with antibiotics and settled without problem. In two patients the prosthetic tube became displaced into the stomach, in one patient the displacement was only evident when a chest radiograph was taken for a chest infection. He did not develop dysphagia and died six days later. The other patient developed intermittent upper abdominal pain which may have been related to the displaced tube. This patient also had recurrent dysphagia (see previous section). One patient had the sensation of the tube in the pharynx and the tube was repositioned. Again this patient did not develop dysphagia and died four weeks later. A patient with a lesion at the gastro-oesophageal junction developed pain after insertion of the tube caused by reflux oesophagitis. Severe bleeding requiring transfusion of four units of blood occurred in one patient. Patients receiving intubation had significantly more complications than those treated with the laser only $(\mathrm{p}<0.05$, Fisher's exact test).

\section{Discussion}

The incidence of tumours of the cardia and oesophagus is increasing in England and Wales. ${ }^{18}$ Only $40 \%$ of patients, however, will be suitable for surgery or radical radiotherapy. ${ }^{5}$ Therefore the aim of most treatment remains palliative. Advances in radiotherapy has meant that intracavitary radiation is now a practical method of 
therapy and provides relief of dysphagia in $70 \%$ of patients with squamous carcinomas and $60 \%$ with adenocarcinoma. ${ }^{19}$ This technique requires a general anaesthetic and is inappropriate if there is complete oesophageal occlusion. The two most widely used methods for the endoscopic palliation of malignant dysphagia are endoscopic intubation and laser recanalisation. Direct comparison of these two techniques has proved difficult in our practice as some patients were sent because endoscopic intubation had failed, and others were initially unsuitable for intubation because of the degree of obstruction or the nature of the tumour. It was therefore clear that the number of exclusions from the trial would be $20-30 \%$ if we were to randomise patients directly for laser therapy or intubation. Those excluded would be the patients with the most severe disease and degree of dysphagia. The only complication of the combined procedure that became evident was early slippage of the tube. In one patient this meant removal from the trial, because of the patient's preference not to have repeat endoscopic intubation. Intubation after 10 days did not result in early slippage.

The mean dysphagia grade measured for the month correlated well with the VAS of dysphagia taken at the monthly LASA assessment. It may therefore be valid to measure dysphagia at one time using LASA. The dysphagia grade for patients treated with repeated laser therapy and those with a prosthetic tube is similar. We observed from the diary cards that swallowing ability of patients with a prosthetic tube remained relatively constant. Many patients treated with the laser can at some time manage a near normal diet but there is greater fluctuation in the quality of swallowing. This may be expected from the nature of the treatment with laser therapy patients requiring repeated sessions to maintain the oesophageal lumen. Mellow and Pinkas found that repeat laser sessions were required four to 15 weeks (mean seven) after the initial laser sessions. ${ }^{20}$ We have always treated patients at monthly intervals to prevent and forestall recurrent dysphagia. ${ }^{11}$

Few trials of new cancer therapy attempt to measure quality of life, ${ }^{21}$ and if they do so they often use the Karnofsky performance status scale. ${ }^{22}$ This scale has shown poor correlation between patient's and doctor's scores. ${ }^{21}$ In this study we chose to use two scales that had been used in the assessment of cancer patients with terminal illness. One was a physician's assessment (QLI) and the other was a patient's self assessment (LASA). This allowed us to correlate the physician's assessment with that of the patient. The QLI does not specifically examine the predominant symptom of dysphagia. We did not regard this as a defect as this item was examined separately and it is difficult to determine how much weight individual patients attribute to their dysphagia particularly if they are anorexic with advanced or metastatic disease. This criticism is partly invalidated since we found a good correlation between the dysphagia grade recorded and the QLI. The main advantage was that it is easy to use and lends itself well for repeated follow up.

The LASA measurement correlated well with the QLI. The main criticism of VAS as a means of assessing symptoms has been the doubt expressed by some workers that the measurement does not correspond with the symptom or experience under examination. ${ }^{21}$ The only individual symptom that we could examine by two separate methods was dysphagia and we found a good correlation between the dysphagia diary and the dysphagia VAS. The major problem with the LASA was that it was time consuming and some patients found it difficult to use. There was a tendency to use either end and the midpoint of the scale preferentially. It was necessary therefore to be available while the patient was filling in the form. Patients who survived for some time and had repeated assessments became very able at using this instrument.

Patients in both groups showed improvement in the mean quality of life score compared with the pretreatment score although this was not significant. The best QLI score was significantly better than the pretreatment score, indicating that at some time in the remainder of the patient's life their quality of life was improved. There are no data on the quality of life of patients who receive only supportive therapy until death. It is possible to speculate that as the natural history of this disease is a gradual decline, a treatment that maintains the mean post treatment quality of life may perhaps represent an improvement. Laser therapy alone and laser/ intubation were equally effective and there was no difference in the quality of life scores in either group. There are also little data on the effect of other methods of treatment on the quality of life of patients with malignant dysphagia. One study of patients interviewed one year after oesophageal resection for carcinoma concluded that there was no evidence of a diminished quality of life in these patients. ${ }^{23}$ None of our patients survived one year after the start of therapy and direct comparison is inappropriate. We concluded that provided dysphagia was relieved by whatever means the quality of life was maintained. Despite the difference in the complication and recurrent dysphagia rate this is not reflected as a difference in the quality of life assessments. This may be because these complications were not major and we were able to offer treatment for them.

The major difference between the two groups was in the complication and recurrent dysphagia rate. Only $10 \%$ of patients treated with repeated laser therapy developed complications of treatment, whereas $40 \%$ had complications attributable to the insertion or presence of a prosthetic tube in the oesophagus. These results are comparable with those reported by others. ${ }^{10} 11$ It is important to note that the three pharyngeal perforations after intubation were only detected after contrast radiology. They appeared to be of no significance in two patients and might well have gone undetected. Perforation either after laser therapy or intubation can be treated conservatively and we had no procedure related mortality. Large series have reported a mortality of $3-13 \%$ for intubation ${ }^{9}$ and we reported a mortality for laser therapy for the treatment of 76 patients of $5 \%$." A perforation rate of 6-8\% seems to be a constant feature of fibreoptic intubation and dilatation, and no decrease has 
been noticed despite increased experience. ${ }^{7}$ In contrast we have found a learning period associated with endoscopic laser therapy and have noticed a decrease in perforation and complication rate with increasing experience. Most perforations associated with laser therapy can be attributed to a preliminary dilatation, or attempted dilatation of a laser induced fibrous stricture. ${ }^{11}$

Recurrent dysphagia is more common in patients with a prosthetic tube $(45 \%)$, predominantly because of food bolus obstruction. Tumour overgrowth of the tube may be managed by repositioning of the tube, but we have found this to be difficult and prefer endoscopic laser therapy. Recurrent dysphagia in the laser treated patients occurred less frequently $(25 \%)$ and was caused by rapid growth of intraluminal tumour, or extrinsic compression of the oesophagus by extraluminal tumour.

In conclusion it is clear that both laser therapy or intubation are effective at relieving malignant dysphagia. The advantage of intubation is that it is a theoretically a 'one-off' treatment. It is, however, associated with more complications but these are generally minor and can be effectively treated. Both treatments are complimentary and equally effective in maintaining the patient's quality of life. In patients with a fistula to the trachea there can be no alternative except immediate intubation. Similarly patients with a tight impassable stricture are best treated with laser therapy. We have also identified other patients where laser therapy or intubation are most appropriate. ${ }^{24}$ Laser therapy is best used if the tumour occurs high in the oesophagus, is largely exophytic, has caused significant bleeding or is occluding a prosthetic tube. Intubation is most useful if the tumour is extrinsic and rapidly growing. There may be theoretical objections to the placement of a tube across the gastrooesophageal junction allowing reflux and regurgitation. This occurred in one of our patients. At present there are no data to compare the cost of both methods of therapy, but it is clear that intubation is likely to be a more cost effective option in most centres, where there is not a multipurpose laser endoscopy unit. Overall, the results of this trial suggest that intubation should remain an effective first line treatment in most patients, laser therapy being restricted to specialist centres, and used for the management of difficult oesophageal strictures by those with special expertise or where a prosthetic tube cannot be placed. Both techniques should be available for the management of patients with malignant dysphagia.

1 Earlam R, Cunha-Melo JR. Oesophageal squamous cell carcinoma: I. A critical review of surgery. Br f Surg 1980; 67: $381-90$

2 Earlam R, Cunha-Melo JR. Oesophageal squamous cell carcinoma; II. A critical review of radiotherapy. Br f Surg 1980 67: 457-61.

3 Leverment JN, Milne DM. Oesophagogastrectomy in the treatment of malignancy of the thoracic oesophagus and treatment of malignancy of the

4 Watson A. A study of the quality and duration of survival following resection, endoscopic intubation and surgica intubation in oesophageal carcinoma. Br f Surg 1982; 69: 585-8.

5 Belsey RHR. Palliative management of oesophageal carcinoma. Am F Surg 1980; 139: 292-5.

6 Orringer MB. Palliative procedures for oesophageal cancer. Surg Clin North Am 1983; 63: 941-50.

7 Bennett JR. Intubation of gastro-oesophageal malignancies: a survey of current practice in Britain, 1980. Gut 1981; 22: 336-8.

8 Lishman DH, Dellipiani AW, Devlin HB. The insertion of oesophagogastric tubes in malignant strictures: endoscopy or surgery. Br 7 Surg 1980; 67: 257-9.

9 Tytgat GNJ, Bartelsman JFWM, Den Hartog Jager FCA Huibregtse K, Mathus-Vliegen EMH. Upper intestinal and biliary tract endoprothesis. Dig Dis Sci 1986; 31: 57S-75S.

10 Pfleiderer AG, Goodall D, Holmes GKT. The consequences and effectiveness of intubation in the palliation of dysphagia due to benign and malignant strictures affecting the oesophagus. Brf Surg 1982; 69: 356-8.

11 Krasner N, Barr H, Skidmore C, Morris Al. Palliative laser therapy for malignant dysphagia. Gut 1987; 28: 792-8.

12 Bown SG, Hawes R, Matthewson K, et al. Endoscopic laser palliation for advanced malignant dysphagia. Gut 1987; 28 . 799-807

13 Atkinson M, Ferguson R, Parker GC. Tube introducer and modified Celestin tube for use in palliative intubation of oesophagogastric neoplasms at fibreoptic endoscopy. Gut 1978; 19: 669-71

14 Ogilvie AL, Dronfield MW, Ferguson R, Atkinson $M$ Palliative intubation of oesophagogastric neoplasms at fibreoptic endoscopy. Gut 1982; 23: 1060-7.

15 Spitzer WO, Dobson AJ, Hall J, et al. Measuring the quality of life of cancer patients. A concise QL-index for use by physicians. F Chron Dis 1981; 34: 585-97.

16 Prestman TJ, Baum M. Evaluation of quality of life in patients receiving treatment for advanced breast cancer. Lancet 1976 ii: $899-901$.

17 Brooks PT, Troop AC, Barr H, Krasner N. Massive pneumatoperitoneum following laser therapy of inoperable oesophageal carcinoma. Clin Radiol 1988; 39: 305-7.

18 Earlam RJ, Cunha-Melo JR, Donnan SPB, Evans SJW. The epidemiology of oesophageal cancer with special reference to England and Wales. Ital $\Im$ Gastrenterol 1982; 14: 244-9.

19 Rowland CG, Pagliero KM. Intracavitary irradiation in palliation of carcinoma of the oesophagus and cardia. Lancet 1985 ii: 981-2.

20 Mellow MH, Pinkas H. Endoscopic laser therapy for malignancies affecting the esophagus and gastroesophageal junction. Arch Intern Med 1985; 145: 1443-6.

21 Clark A, Fallowfield LJ. Quality of life measurements in patients with malignant disease: a review. $\mathcal{J} R$ Soc Med 1986; 79: 165-9.

22 Karnofsky DA, Burchenal JH. The clinical evaluation of chemotherapeutic agents in cancer. In: McLeod CM, ed. Evaluation of chemotherapeutic agents in cancer. New York Columbia University Press, 1949: 191-205.

23 Sugimachi K, Maekawa S, Koga Y, Ueo H, Inokuchi K. The quality of life is sustained after operation for carcinoma of the oesophagus. Surg Gynecol Obstet 1982; 162: 544-6.

24 Krasner N, Barr H, Morris AI, Walker RJ. Laser therapy and intubation for oesophageal malignancy: practicalities and problems [Abstract]. Gut 1986; 27: A1253-4 